\title{
Thermal analysis of periodic sliding contact on a braking tribometer
}

\author{
Monica Siroux $^{\mathrm{a}, *}$, Anne-Lise Cristol-Bulthé ${ }^{\mathrm{b}}$, Yannick Desplanques ${ }^{\mathrm{b}}$, \\ Bernard Desmet ${ }^{\mathrm{a}}$, Gérard Degallaix ${ }^{\mathrm{b}}$ \\ ${ }^{\text {a }}$ Laboratoire de Mécanique et Energétique (LME EA 2447) UVHC, Le Mont Houy, 59313 Valenciennes Cedex 9, France \\ ${ }^{\mathrm{b}}$ Laboratoire de Mécanique de Lille (LML UMR CNRS 8107), Ecole Centrale de Lille, BP 48, 59651 Villeneuve d'Ascq Cedex, France
}

Received 6 July 2007; accepted 27 December 2007

Available online 12 January 2008

\begin{abstract}
The thermal behaviour of a brake disc during a periodic sliding contact in braking situations is studied. The experimental tests are performed on a braking tribometer, on two types of materials used in railway applications: an organic matrix composite (OMC) for the pin and a grey cast iron for the disc. The mass temperature of the brake disc is measured $2 \mathrm{~mm}, 5 \mathrm{~mm}$ and $7 \mathrm{~mm}$ under the friction surface during a succession of stop brakings. Experimental data and an analytical model of thermal conduction determine the disc surface temperature evolution during the succession of stop brakings. Results are then compared with those estimated by pyrometry; a good correlation is found. Finally, the complex thermal transfer function of the disc, defined as the ratio of the mass and surface temperature of the disc, quantifies the temperature attenuation and the phase shift of the thermal wave in the disc.
\end{abstract}

(C) 2008 Elsevier Ltd. All rights reserved.

Keywords: Braking; Tribometer; Periodic sliding contact; Temperature

\section{Introduction}

In railway braking, during a succession of stop brakings, the brake disc is subject to periodic thermomechanical stress which can generate, on the one hand, a degradation of the friction performances and, on the other hand, a high level of wear due to materials damage. In this context, knowledge of the disc surface temperatures is an essential element for the study of the tribological behaviour of materials in periodic sliding contact.

Several authors have studied the heat transfer of two solid interfaces in sliding contact. Denape and Laraqi $[1,2]$ presented a review of the means, experimental as well as theoretical, to evaluate the temperature maps gradients in a sliding contact. Lesquois [3] studied the tribological and thermal phenomena in a projectile shooting. Dalverny [4] proposed a model and an experimental study to evaluate

\footnotetext{
* Corresponding author. Tel.: +33 3275119 88; fax: +33 327511961 . E-mail address: Monica.Siroux@univ-valenciennes.fr (M. Siroux).
}

the mean and flash temperature during the rubbing contact on a braking tribometer. Desplanques [5] presented a thermal representativeness of tribological reduced-scale testing. The inverse heat conduction methods were applied by Raynaud [6] in order to estimate both the temperature and the heat flux at the surface of a metallic pin that slides on a rotating disc and by Kusiak [7] to evaluate the influence of tool coatings on the heat transfer in the tool during machining.

Other authors have considered conductive heat transfer through periodic intermittent contact. Howard [8] proposed an experimental study of heat transfer through periodically contacting surfaces and found that a significant reduction in thermal resistance could be achieved by increasing the impact with which the surfaces made contact. A theoretical and experimental study of heat transfer in a valve-seat periodic contact in an internal combustion engine was presented by Couedel [9]. Thanks to a special set-up, it was possible to measure the mean and periodic temperature fields and show that the mean contact resistance depends strongly on frequency. Wang $[10,11]$ 


\section{Nomenclature}

$\begin{array}{ll}a & \text { thermal diffusivity }\left(\mathrm{m}^{2} / \mathrm{s}\right) \\ b & \text { thermal effusivity }\left(\mathrm{J} / \mathrm{m}^{2} \mathrm{~K} \mathrm{~s}^{1 / 2}\right) \\ C & \text { constant of integration } \\ D & \text { constant of integration } \\ d & \text { thermal wave depth }(\mathrm{m}) \\ f & \text { frequency }(\mathrm{Hz}) \\ H & \text { thermal transfer function } \\ k & \text { thermal conductivity }(\mathrm{W} / \mathrm{m} \mathrm{K}) \\ p & \text { mean contact pressure }(\mathrm{Pa}) \\ R & \text { mean friction radius }(\mathrm{m}) \\ q & \text { thermal diffusion parameter }\left(\mathrm{m}^{-1}\right) \\ S & \text { surface }\left(\mathrm{m}^{2}\right) \\ T & \text { temperature }(\mathrm{K}) \\ v_{g} & \text { sliding velocity }(\mathrm{m} / \mathrm{s}) \\ x & \text { coordinate } \\ & \\ \text { Greek } & \text { symbols } \\ \alpha & \text { heat flux partition coefficient } \\ \varphi & \mu \text { heat flux density }\left(\mathrm{W} / \mathrm{m}^{2}\right)\end{array}$

$\begin{array}{ll}\Phi & \text { heat flux (W) } \\ \mu & \text { friction coefficient } \\ \theta & \text { phase of the thermal wave (rad) } \\ \omega & \text { pulsation }(\mathrm{rad} / \mathrm{s})\end{array}$

Subscripts

d disc

p pad

$12 \mathrm{~mm}$ under the friction surface of the disc

0 disc surface

\author{
Superscript \\ complex
}

presented a quadrupole model to solve the conductive transfer in a one-dimensional periodic contact. This modeling makes it possible to determine the thermal resistance of contact and highlight the phenomenon of constriction. An experiment of intermittent contact was carried out and the results were compared with theoretical solutions.

However the study of the periodic sliding contact, characteristic of a succession of stop brakings, is, to the best of our knowledge, non-existent in the pertinent literature. This article is about the thermal characterization of a brake disc during the periodic sliding contact in braking situations. The experimental study is performed on a braking tribometer. The mass temperature of the brake disc is measured $2 \mathrm{~mm}, 5 \mathrm{~mm}$ and $7 \mathrm{~mm}$ under the friction surface during a succession of stop brakings. Experimental data and an analytical model of thermal conduction determine both the surface disc temperature evolution during the succession of stop brakings and the complex thermal transfer function of the disc, defined as the ratio of the mass temperature and surface temperature of the disc.

\section{Experimental study}

\subsection{Experimental set-up}

The tests are performed in the Laboratoire de Mécanique de Lille on a pad-on-disc braking tribometer developed to reproduce at reduced-scale the contact stress observed between disc and pad at full-scale during railway braking [12]. This device can be used to reproduce different brakings: stop braking, a succession of stop brakings with heat accumulation and hold braking. Fig. 1 shows the tribometer architecture: the disc is driven in rotation by the electric motor with an initial sliding velocity of up to $70 \mathrm{~m} \mathrm{~s}^{-1}$ and two hydraulic actuators apply the normal load on the pad leading to a maximal mean contact pressure of up to $1 \times 10^{7} \mathrm{~Pa}$. In order to reproduce surface mean temperature elevations observed at full-scale, a scale conversion rule was developed [13]. The parametric triplet composed of the mean contact pressure, initial sliding velocity and braking duration can be chosen to reproduce thermal loadings observed at full-scale. The tribometer measurement instruments measure the rotation speed (motor tachymeter) and the pin-disc effort components (3D piezoelectric sensor). K-type thermocouples measure the ambient temperature and the disc mass temperature, the absolute error on this temperature is $0.3^{\circ} \mathrm{C}$. In order to position these thermocouples, the penetration depth of the thermal wave in the disc is calculated. This value is $25 \mathrm{~mm}$, for the frequency of $6.71 \times 10^{-3} \mathrm{~Hz}$ used for the tests, and represents the limit of positioning of the sensors under the friction zone. In order to observe thermal fluctuations, several thermocouples were placed at $2 \mathrm{~mm}$ $\left(T_{2} \mathrm{~mm}\right), 5 \mathrm{~mm}\left(T_{5} \mathrm{~mm}\right)$ and $7 \mathrm{~mm}\left(T_{7} \mathrm{~mm}\right)$ under the friction surface on the mean friction radius $R=100 \mathrm{~mm}$ (Fig. 2). An infrared pyrometer INFRATHERM IP10 is used to estimate the temperature on the mean radius of the disc track when contact stops. The pyrometer characteristics are: measurement range from 75 to $550{ }^{\circ} \mathrm{C}$, spectral range from 2 to $2.8 \mu \mathrm{m}$, spot diameter of $2.2 \mathrm{~mm}$, precision of $1.5^{\circ} \mathrm{C}$ and response time of $2 \mathrm{~ms}$. Both the value and evolution of emissivity of the disc surface during braking are unknown. The radiative behaviour of the disc surface is considered as that of a black body and consequently only a rough value of the surface temperature is obtained. 

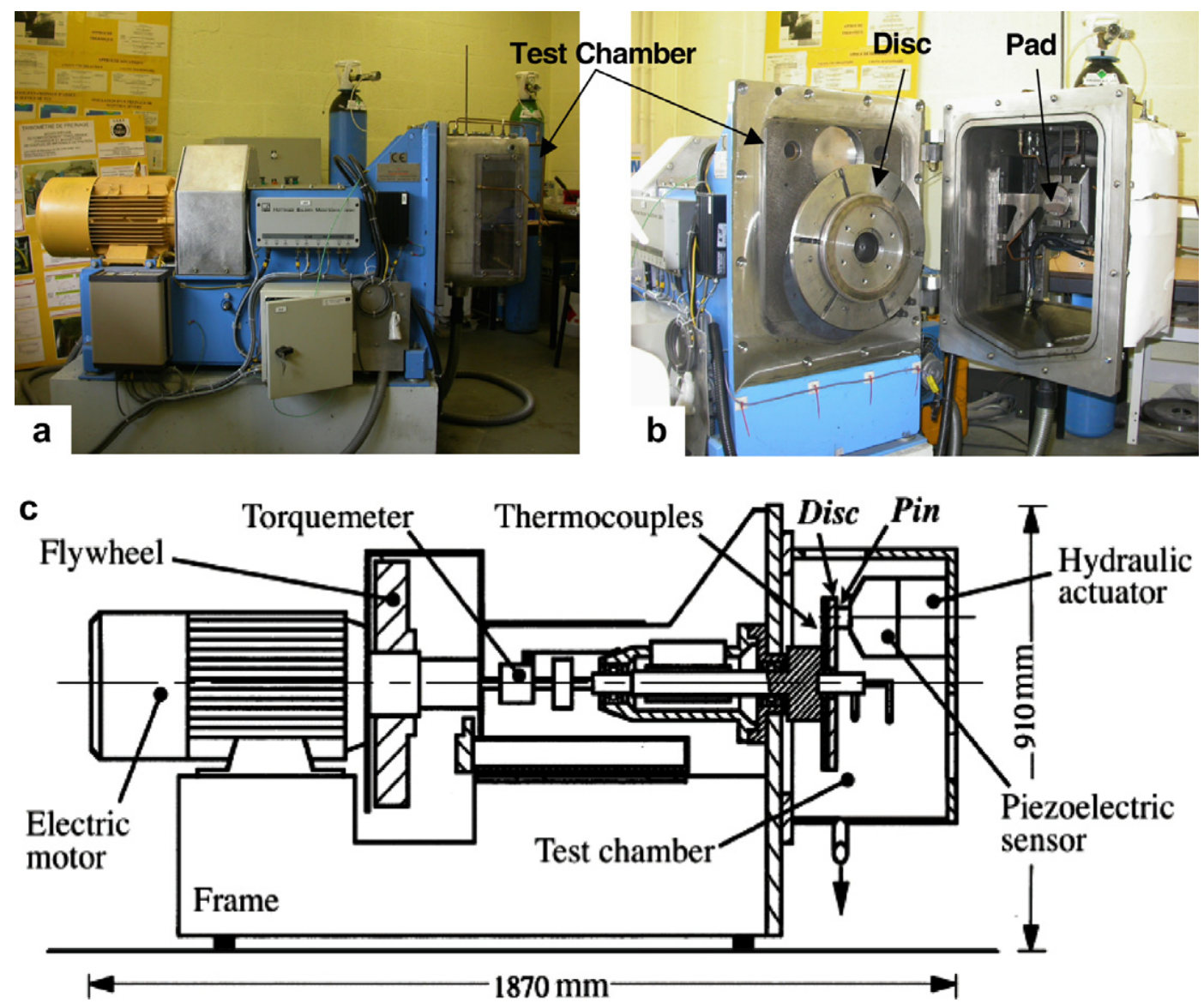

Fig. 1. Braking tribometer: photo with closed (a) and open test chamber (b) and schematic drawing of the tribometer (c).
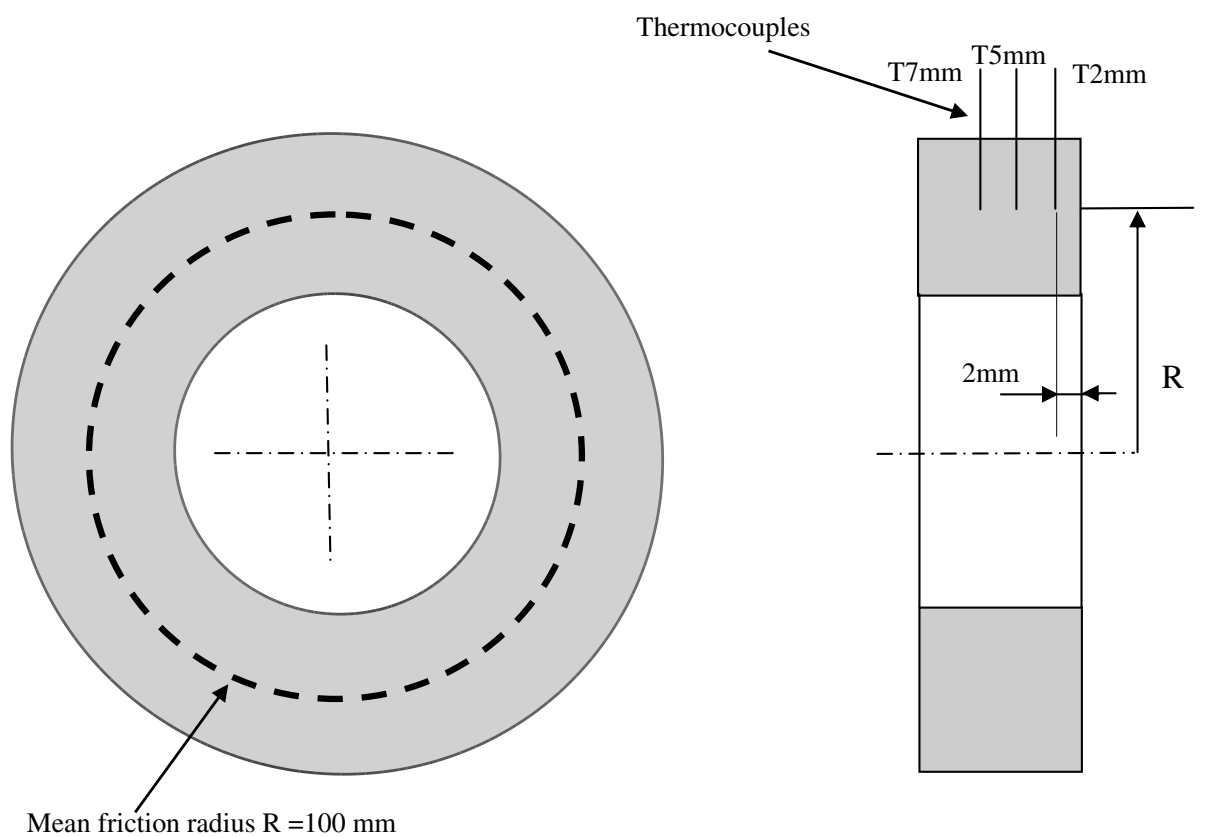

Fig. 2. Brake disc: location of the thermocouples.

\subsection{Tests performed}

The tests are performed on two types of materials used in railway applications: an organic matrix composite
(OMC) for the pin and a grey cast iron for the disc. The pin shape was lengthened in the sliding direction as shown on Fig. 3 with a width of $16 \mathrm{~mm}$ and a thickness of $14 \mathrm{~mm}$. The disc has a friction track of $17 \mathrm{~mm}$ wide and $22 \mathrm{~mm}$ 


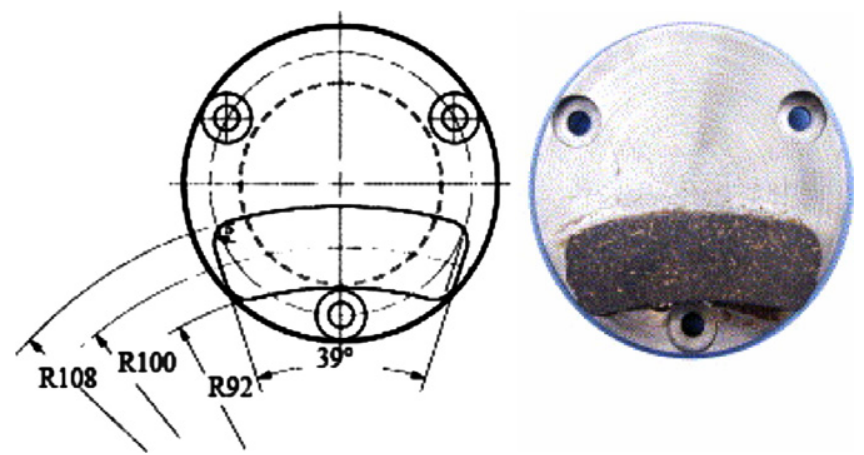

Fig. 3. Drawing and picture of a pin specimen showing the lengthened shape of the friction surface.

Table 1

Thermal and geometric characteristics of the disc and pad

\begin{tabular}{|c|c|c|c|c|c|c|}
\hline & Material & $\begin{array}{l}k \\
\left(\mathrm{~W} \mathrm{~m}^{-1} \mathrm{~K}^{-1}\right)\end{array}$ & $\begin{array}{l}a \\
\left(\mathrm{~m}^{2} \mathrm{~s}^{-1}\right)\end{array}$ & $\begin{array}{l}b\left(\mathrm{~J} \mathrm{~m}^{-2} \mathrm{~K}^{-1}\right. \\
\left.\mathrm{s}^{-1 / 2}\right)\end{array}$ & $\begin{array}{l}S \\
\left(\mathrm{~m}^{2}\right)\end{array}$ & $\alpha$ \\
\hline Disc & Cast iron & 44.7 & $1.32 \times 10^{-5}$ & 12,318 & 0.0101 & 0.9 \\
\hline $\mathrm{Pad}$ & OMC & 12 & $8.28 \times 10^{-6}$ & 4171 & 0.0011 & \\
\hline
\end{tabular}

Table 2

Stop braking parameters

\begin{tabular}{ll}
\hline Mean contact pressure & $0.86 \mathrm{MPa}$ \\
Initial sliding velocity & $15.7 \mathrm{~m} / \mathrm{s}$ \\
Braking duration & $21.9 \mathrm{~s}$ \\
Friction coefficient & 0.33 \\
Energy dissipated during the braking & $53 \mathrm{~kJ}$ \\
Heat flux density absorbed by the disc & $4.75 \times 10^{5} \mathrm{~W} / \mathrm{m}^{2}$ \\
Heat flux density absorbed by the pad & $1.61 \times 10^{5} \mathrm{~W} / \mathrm{m}^{2}$
\end{tabular}

thick. The mean friction radius is $100 \mathrm{~mm}$. The thermal and geometric characteristics of the specimens are given in Table 1.

The test sequence is composed of a succession of 30 identical stop brakings. The stop braking parameters are given in Table 2, the chosen parametric triplet implies that the energy dissipated during braking is $53 \mathrm{~kJ}$. By taking account of the friction surfaces and $\alpha$ values, the heat flux absorbed by the pad and disc are calculated. The braking period during the succession is equal to $149 \mathrm{~s}$, which covers speed increase, speed stabilisation, braking duration and cooling time after the stop and before the next braking. The succession leads to a stabilized periodic regime in the final brakings of the sequence [14].

\section{Analytical modeling}

This study is based on a one-dimensional disc (Fig. 4) in periodic sliding contact with the pad $(x=0)$. The sliding contact thermal resistance between the disc and the pad $[2,9-11]$ is neglected in this study, we estimate only the brake disc temperature.

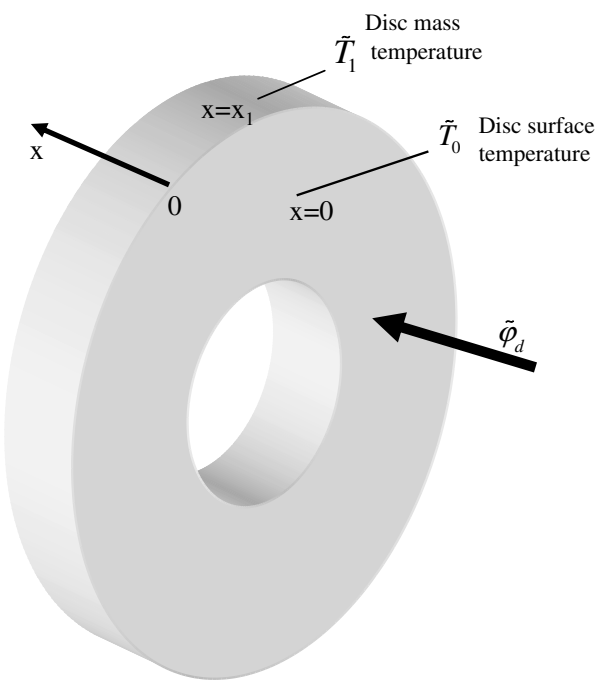

Fig. 4. Conduction model.

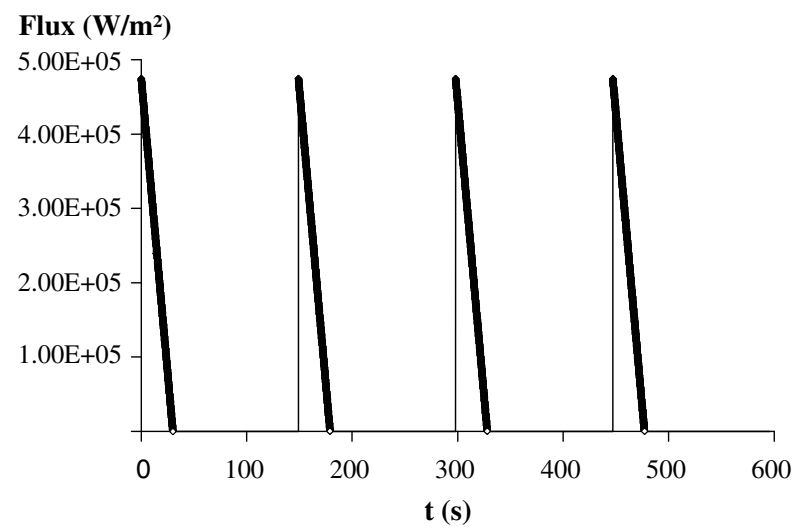

Fig. 5. Evolution of the heat flux density dissipated trough the disc during the final four stop brakings ( - experimental data).

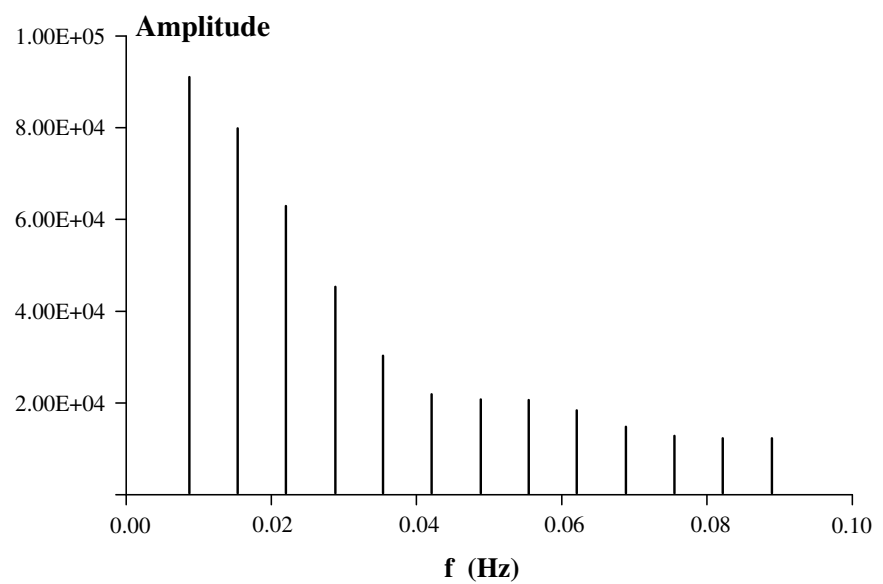

Fig. 6. Amplitude spectra for the heat flux density absorbed by the disc during the final four stop brakings. 
The thermal properties of the disc being supposed con- $\left.\quad k(\mathrm{~d} \widetilde{T} / \mathrm{d} x)\right|_{x=0}=-\tilde{\varphi}_{d}$ stant, the heat balance equation can be written:

$\partial^{2} \widetilde{T} / \partial x^{2}-(\mathrm{j} \omega / a) \widetilde{T}=0$

$\widetilde{T}$ with $\mathrm{j}=\sqrt{-1}$ and complex temperature. by:

The general evolution of the disc temperature is given

$\widetilde{T}=\widetilde{C} \sinh (\tilde{q} x)+\widetilde{D} \cosh (\tilde{q} x)$

with $\tilde{q}=\sqrt{\mathrm{j} \omega / a}, \widetilde{C}$ and $\widetilde{D}$ constants of integration

The boundary conditions are:

For $x=0$ :

For $x=x_{1}$ :

$\left.\widetilde{T}\right|_{x=x 1}=\widetilde{T}_{1}$

The heat flux density dissipated through the disc during a succession of stop brakings is a periodic function which depends on the heat flux partition coefficient $\alpha$, friction coefficient $\mu$, mean contact pressure $\mathrm{p}$ and initial sliding velocity $v_{g}$ :

$\tilde{\varphi}_{d}=\alpha \widetilde{\Phi} / S_{\mathrm{d}}$

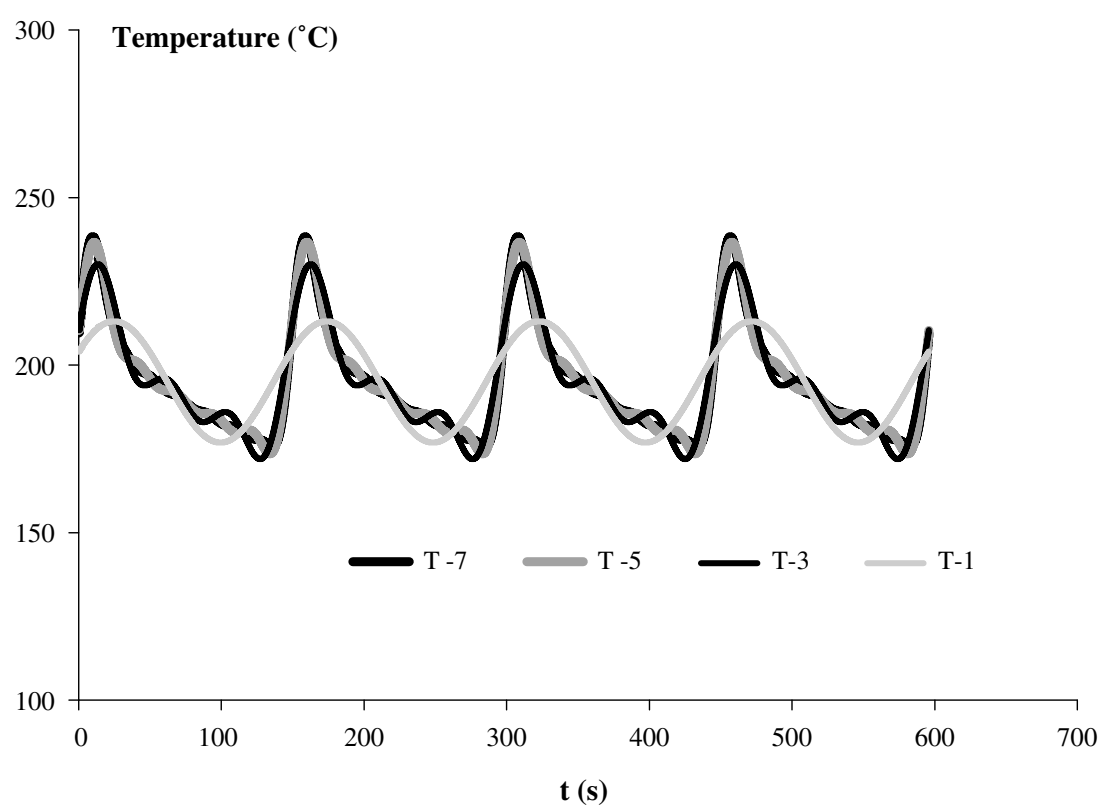

Fig. 7. Influence of harmonics number on the reconstituted surface temperature signal. T-1: fundamental, T-3: the first 3 harmonics, T-5: the first 5 harmonics, T-7: the first 7 harmonics.

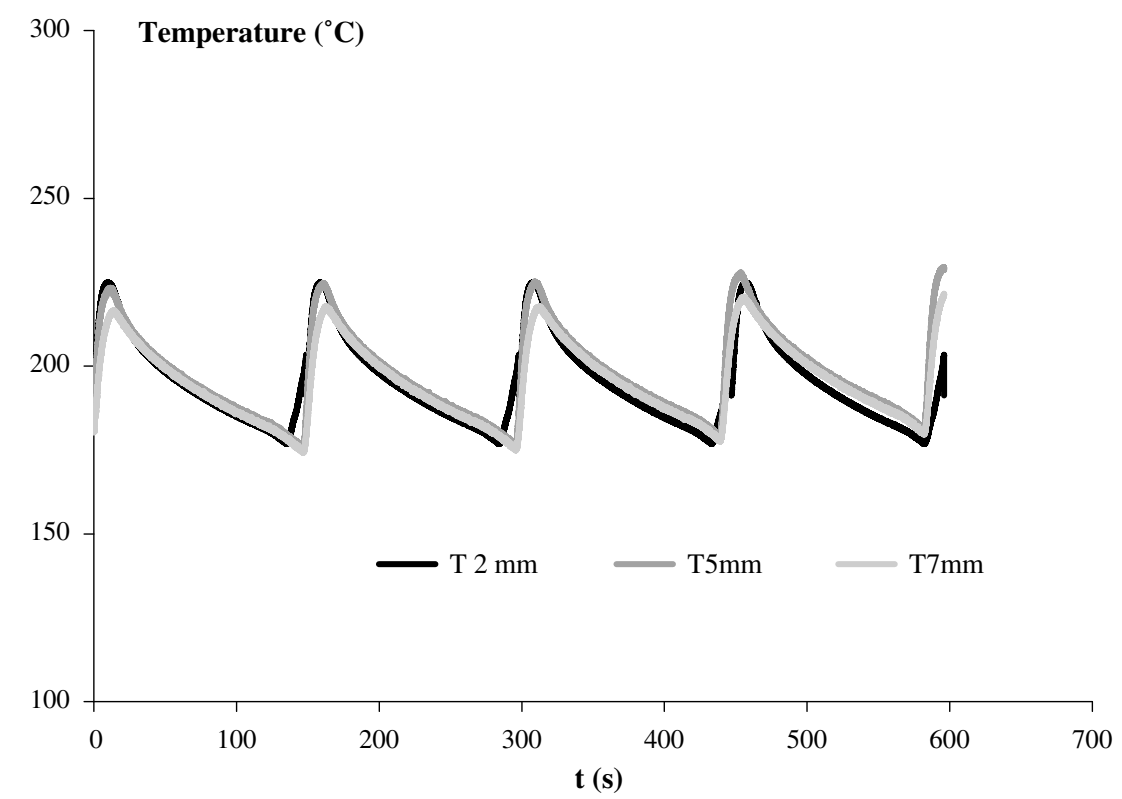

Fig. 8. Evolution of the mass disc temperature during the final four brakings. 
with $\widetilde{\Phi}=|\widetilde{\Phi}| \mathrm{e}^{\mathrm{j} \theta}$ heat flux generated by friction on contact, $|\widetilde{\Phi}|=v_{g} p S_{\mathrm{p}} \mu$ maximum amplitude of heat flux, $\alpha=$ $S_{\mathrm{d}} b_{\mathrm{d}} /\left(S_{\mathrm{d}} b_{\mathrm{d}}+S_{\mathrm{p}} b_{\mathrm{p}}\right)$ heat flux partition coefficient defined as the fraction of the friction heat which goes into the disc [1]. with $S_{\mathrm{d}}, S_{\mathrm{p}}$ disc and pad surface $b_{\mathrm{d}}, b_{\mathrm{p}}$ disc and pad effusivity.

The disc surface temperature can be obtained using the conduction model with a function depending on $\widetilde{T}_{1}$ and heat flux $\widetilde{\varphi}_{d}$ :

$\widetilde{T}_{0}=\widetilde{T}_{1} / \cosh \left(\tilde{q} x_{1}\right)+\tilde{\varphi}_{d} \tanh \left(\tilde{q} x_{1}\right) /(k \tilde{q})$
The thermal transfer function of the disc $\widetilde{H}$, is defined by the relation:

$\widetilde{H}=\widetilde{T}_{1} / \widetilde{T}_{0}$

where $\widetilde{T}_{1}$ and $\widetilde{T}_{0}$ are respectively, the complex disc mass temperature measured $2 \mathrm{~mm}$ under the friction surface and at the complex disc surface temperature.

The expression of $\widetilde{H}$ can be obtained by starting from the conduction model:

$\widetilde{H}=\widetilde{T}_{1} /\left(\widetilde{T}_{1} / \cosh \left(\tilde{q} x_{1}\right)+\left(\tilde{\varphi}_{d} \tanh \left(\tilde{q} x_{1}\right) /(k \tilde{q})\right)\right)$

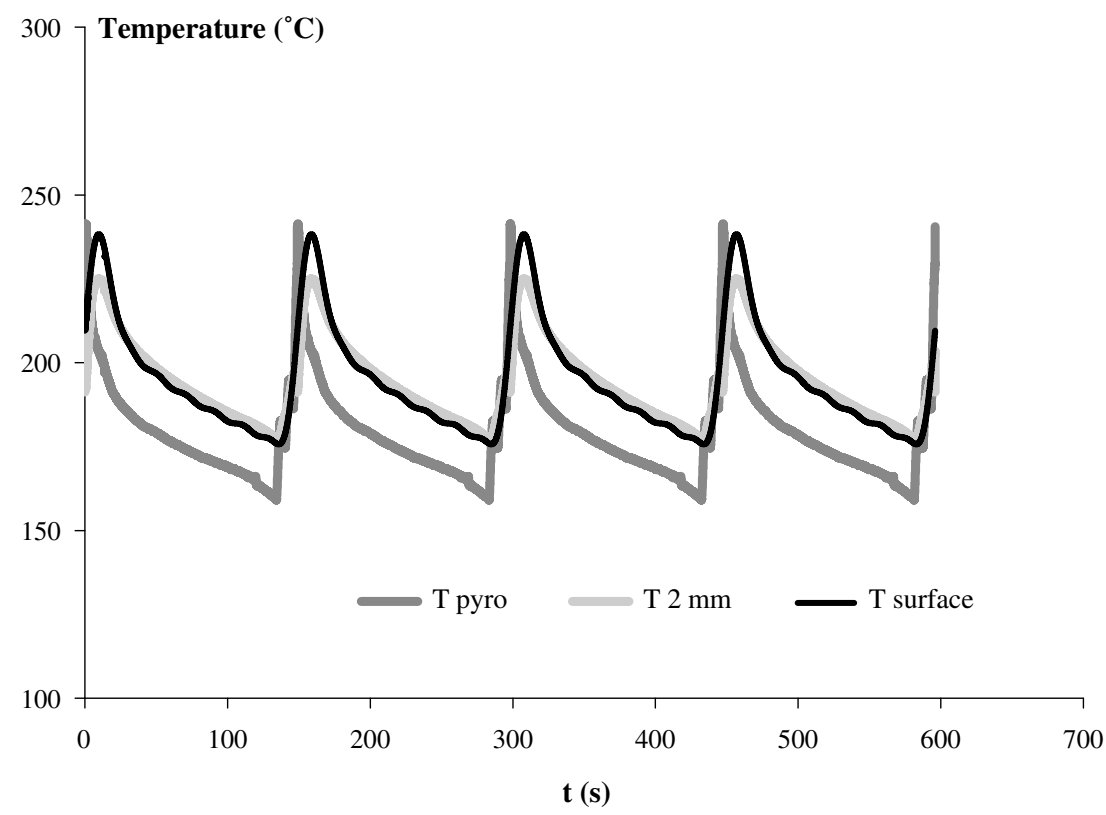

Fig. 9. Evolution of the mass and surface disc temperature during the final four brakings.

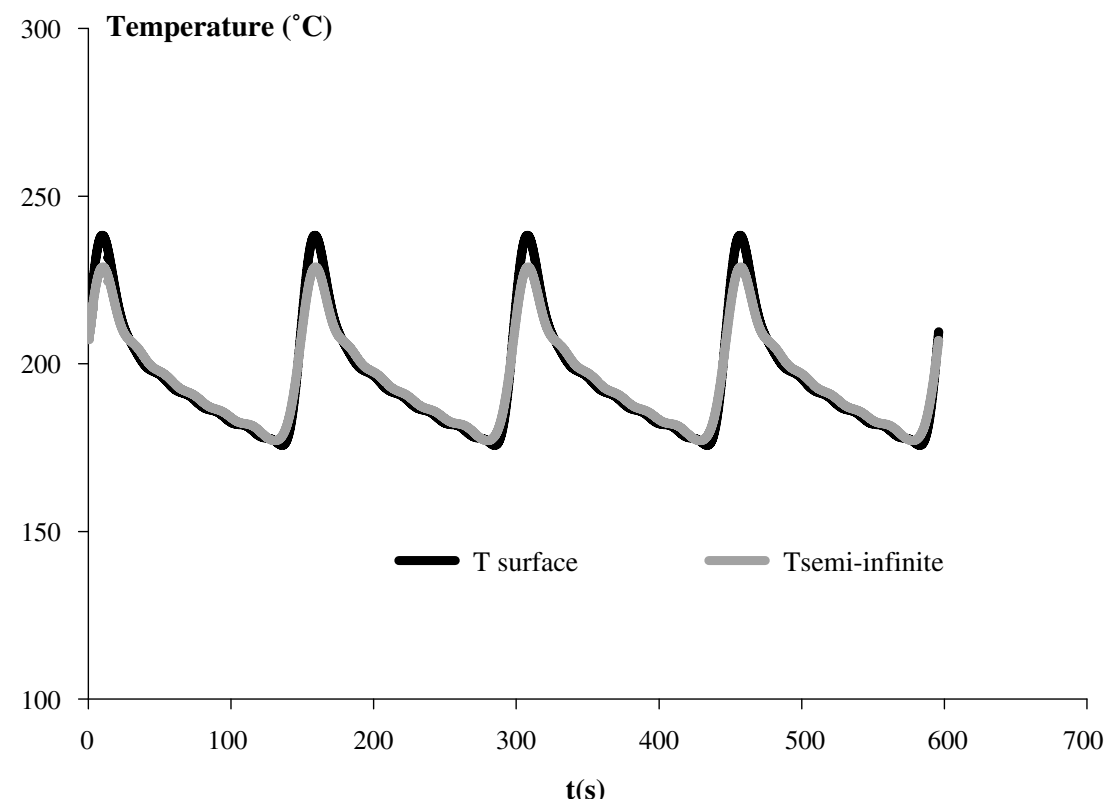

Fig. 10. Comparison between the disc surface temperature and the surface temperature of a semi-infinite disc. 
$\widetilde{H}$ is a complex function, the modulus of which characterizes the temperature attenuation and temperature phase shift between the two sides of the strip [15].

The disc surface temperature $\widetilde{T}_{0}$ and thermal transfer function of the disc $\widetilde{H}$ can thus be given from the disc mass temperature $\widetilde{T}_{1}$ and heat flux density dissipated through the disc $\tilde{\varphi}_{d}$.

\section{Results}

The results presented are those of the tests carried out on the braking tribometer of the Laboratoire de Mécanique de Lille. The test sequence is composed of a succes- sion of 30 stop brakings leading to a stabilized periodic regime in the final four brakings of the sequence.

Fig. 5 presents the evolution of the heat flux density dissipated through the disc during the final four stop brakings of the test sequence. The heat flux density absorbed by the disc is a periodic function of period $149 \mathrm{~s}$, its maximum value corresponds to the maximum sliding velocity at the beginning of braking.

In order to obtain the disc surface temperature $\widetilde{T}_{0}$ (Eq. (6)) the different spectral components are determined for the heat flux density $\tilde{\varphi}_{d}$ and the disc mass temperature $\widetilde{T}_{1}$. Fig. 6 shows the amplitude spectra of the heat flux density absorbed by the disc and obtained by the decomposition of
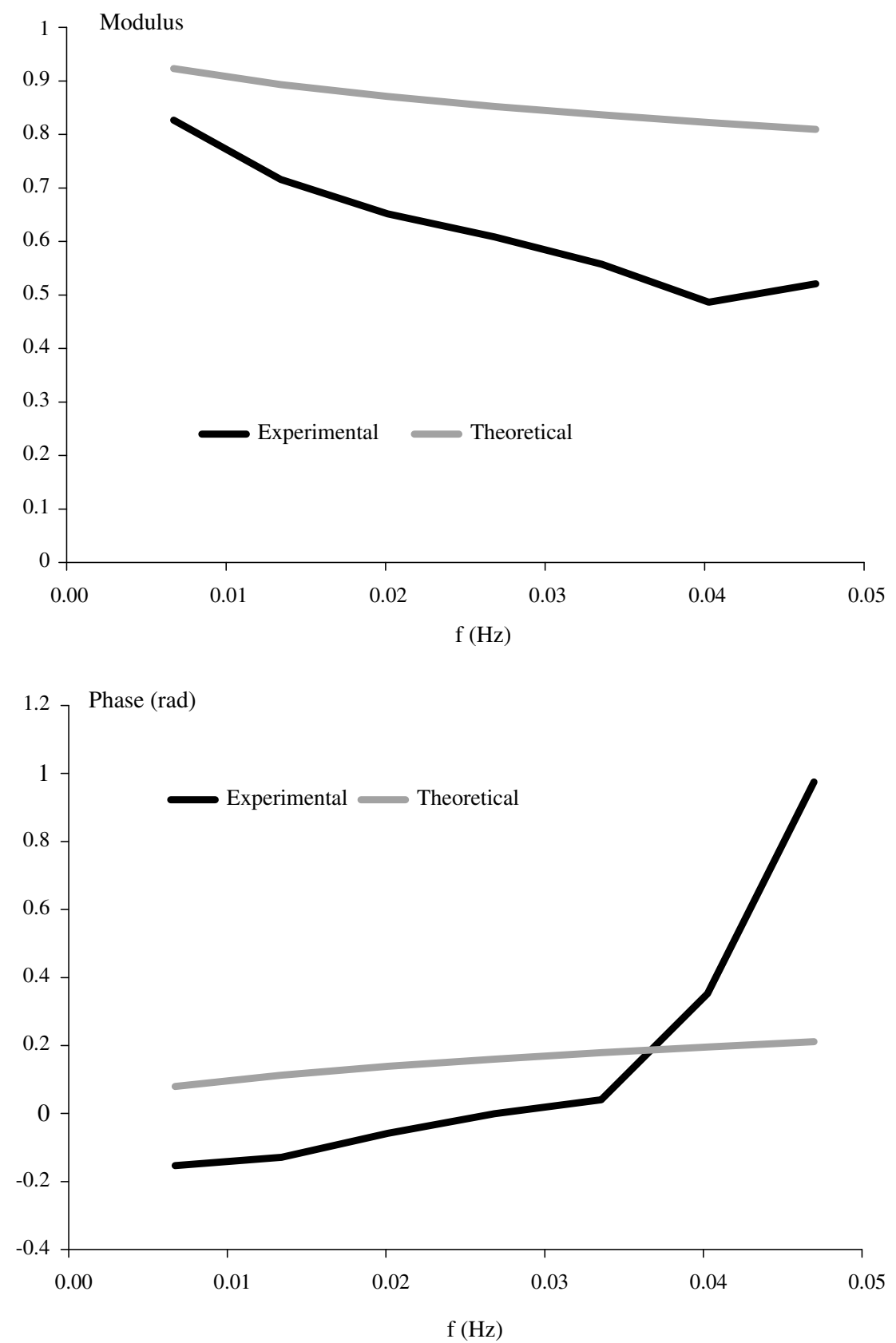

Fig. 11. Modulus and phase of the thermal transfer function of the disc. 
the signal in the Fourier series. It can be seen that the amplitude spectra presents several very marked harmonics.

Fig. 7 shows the influence of the number of harmonics taken into account when calculating the reconstituted surface temperature. T-1 represents the disc surface temperature reconstituted from the fundamental of $\tilde{\varphi}_{d}$ and $\widetilde{T}_{1}$. T-3, T-5 and T-7 represent the disc surface temperature reconstituted respectively from the first 3,5 and 7 harmonics of $\tilde{\varphi}_{d}$ and $\widetilde{T}_{1}$. It can be seen that the reconstituted temperature depends on the number of harmonics taken into account in the calculation: 1,3 and 5. However, there is a slight difference between the signals reconstituted from 5 and 7 harmonics, which means that the first 5 harmonics of the signal are required in the equation.

Fig. 8 presents mass disc temperature evolution during the final four stop brakings of the succession. The mass disc temperature is measured $2 \mathrm{~mm}\left(T_{2} \mathrm{~mm}\right), 5 \mathrm{~mm}\left(T_{5} \mathrm{~mm}\right)$ and $7 \mathrm{~mm}\left(T_{7} \mathrm{~mm}\right)$ under the friction surface by several thermocouples.

Fig. 9 presents mass and surface disc temperature evolution during the final four stop brakings of the succession. The surface temperature $T_{\text {surface }}$ is calculated from Eq. (6), by taking into account the first 7 harmonics of the heat flux density and mass disc temperature. The disc surface temperature is also estimated by pyrometry $T_{\text {pyro }}$ and both calculated and estimated surface temperature curves show good correlation. There is however a difference between calculated and estimated surface temperature $T_{\mathrm{s}}$ and $T_{\text {pyrometer }}$ that can be explained by the following uncertainties: thermophysical properties of the disc (emissivity, conductivity, diffusivity), heat flux partition coefficient and dynamic performances of the pyrometer.

A comparison is also made between the surface temperature of the disc calculated with the analytical model (Eq. (6)) and the surface temperature of a semi-infinite disc
[16] with imposed temperature on $x=x_{1}$. Results are given in Fig. 10 and a good correlation between the two temperatures can be seen.

In order to quantify both temperature attenuation and phase shift of the thermal wave in the disc, the heat transfer function of the disc is determined. Fig. 11 shows the evolution of the modulus and the phase of the thermal transfer function of the disc, in the field of the frequencies corresponding to the first 7 harmonics of the temperature fluctuations. Experimental data is obtained using Eq. (7) and theoretical data is obtained for the heat transfer function of a semi-infinite disc [16]:

$\widetilde{H}_{\text {semi-infinite }}=\mathrm{e}^{-q x_{1}}$

On the one hand, it can be seen that for weak frequencies the modulus and phase of both experimental and theoretical heat transfer are close: the disc has a semi-infinite behaviour. On the other hand, the temperature attenuation and the phase shift increase with frequency and are higher for the experimental thermal transfer function: at high frequency the semi-infinite assumption is not valid.

To assess the validity of our 1D thermal model, we compare the results with 2D simulation (Fig. 12). Heat transfer in the 2D configuration (axisymmetric disc) is modelled by using a space marching method [17]. The temperature is determined for the mean friction radius $(R=100 \mathrm{~mm})$. The disc is divided in two regions: a direct and an inverse region. In the direct region, boundary conditions are given by the temperature measurements: thermocouples placed at $2 \mathrm{~mm}$ and $7 \mathrm{~mm}$ under the friction surface (radius $R=100 \mathrm{~mm}$ ). First, the temperature distribution is obtained in the direct region and second the temperature distributions in the inverse region is determined by the space marching method. The $2 \mathrm{D}$ problem is solved numerically using finite difference algorithm (Cranck Nicholson

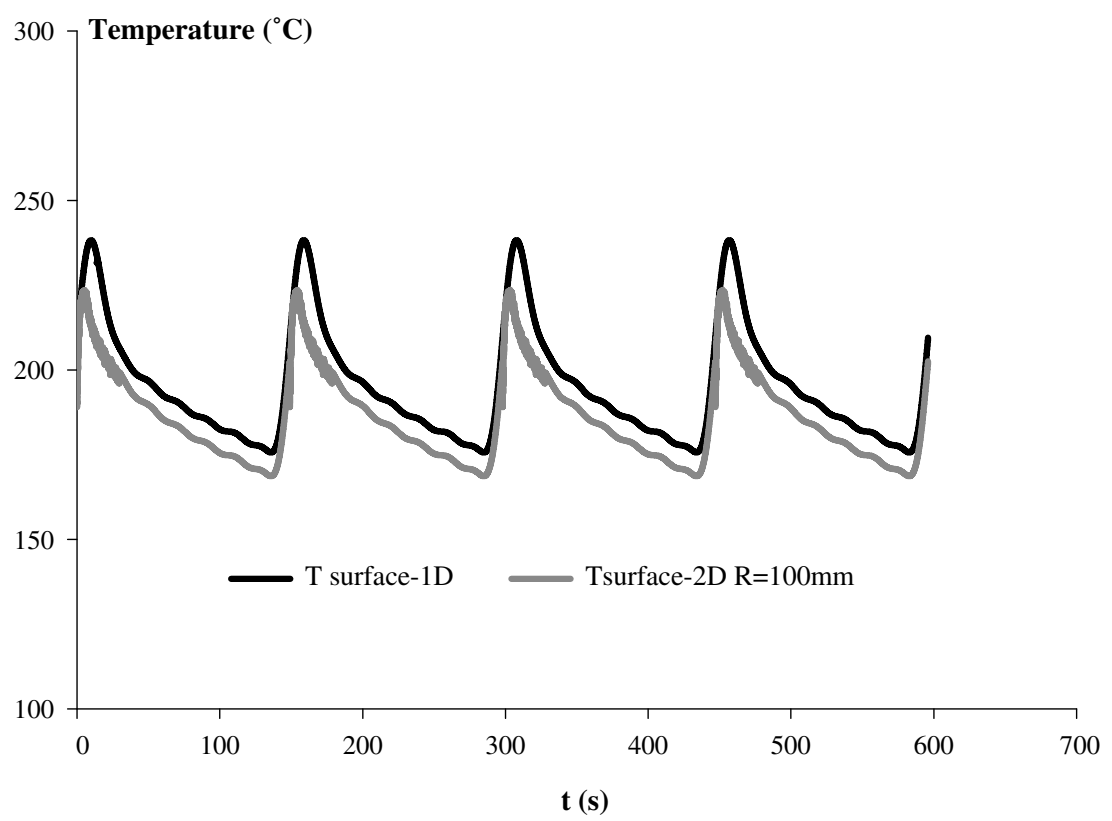

Fig. 12. Comparison with 2D simulation 
scheme for the direct zone and Raynaud method [17] for the inverse zone.) The mean difference between the two models does not exceed 10\% (Fig. 12).

\section{Conclusions}

An experimental study of the thermal behaviour of a braking disc during a periodic sliding contact in braking situations is presented in this article. The experimental study is carried out on a braking tribometer. The tests are performed on two different materials used in railway applications: an organic matrix composite (OMC) for the pin and a grey cast iron for the disc. The mass temperature of the brake disc is measured $2 \mathrm{~mm}$ under the friction surface during a succession of stop brakings. The heat flux density generated by friction on contact is a periodic function which depends on the heat flux partition coefficient, friction coefficient, contact pressure and the initial sliding velocity. It is clearly demonstrated that the brake disc surface temperature evolution can be obtained by starting from the mass disc temperature measurements and an analytical conduction model. Results are concordant with the disc surface temperature estimated by pyrometry. In particular, in order to quantify the temperature attenuation and the phase shift of the thermal wave in the disc, the thermal transfer function of the disc is determined for the first 7 harmonics of the signal. The experimental thermal transfer function of the disc is in good correlation with the theoretical thermal transfer function obtained for a semi-infinite disc. This study must however be further enriched by the determination of the uncertainty on the thermophysical properties of the disc and the heat flux partition coefficient and the sliding contact thermal resistance.

\section{References}

[1] J. Denape, N. Laraqi, Aspect thermique du frottement: mise en évidence expérimentale et éléments de modélisation, Mécanique and Industries 1 (2000) 563-579.

[2] N. Laraqi, A. Bäri, L. Ségui, Temperature and thermal resistance in frictional devices, Applied Thermal Engineering 24 (2004) 25672581.
[3] O. Lesquois, Dégradations dans un contact à grande vitesse en régime transitoire, Thèse de L'école centrale de Lyon (1994).

[4] O. Dalverny, Vie tribologique à chaud et température inter faciale dans des contacts céramiques, Thèse de l'Université Bordeaux (1998).

[5] Y. Desplanques, O. Rousette, G. Degallaix, R. Copin, Y. Berthier, Analysis of tribological behaviour of pad-disc contact in railway braking: Part 1. Laboratory test development, compromises between actual and simulated tribological triplets, Wear 262 (5-6) (2007) 582591.

[6] M. Raynaud, P. Chantrenne, Mesure des températures et flux surfaciques par conduction inverse. Application au frottement sec, Journées Européennes du Freinage 98 Conférence, (1998) 133-140.

[7] A. Kusiak, J. L Battaglia, J. Rech, Tool coating influence on the heat transfer in the tool during machining, Surface and Coatings Technology 195 (2005) 29-40.

[8] J.R. Howard, An experimental study of heat transfer through periodically contacting surfaces, International Journal of Heat and Mass Transfer 19 (1976) 367-372.

[9] D. Couëdel, F. Danès, J.P. Bardon, Experimental study and analysis of heat transfer in a valve-seat periodic contact in an internal combustion engine, advances in heat exchanger design, radiation and combustion, ASME 182 (1991) 59-66.

[10] H. Wang, A. Degiovanni, C. Moyne, Contact thermique périodique: un modèle quadripolaire et une expérience, International Journal of Thermal Sciences 41 (2002) 125-135.

[11] H. Wang, A. Degiovanni, Heat transfer through periodic macrocontact with constriction, International Journal of Heat and Mass Transfer 45 (2002) 2177-2190.

[12] Y. Desplanques, G. Degallaix, R. Copin, Y. Berthier, A tribometer for the study of materials under railway braking conditions, in: G. Dalmaz et al. (Eds.), Tribology Research: From Model Experiment to Industrial Problem, Tribology Series, vol. 39, Elsevier, 2001, pp. 381391

[13] O. Roussette, Y. Desplanques, G. Degallaix, Représentativité thermique d'essais tribologiques à échelle réduite, Comptes Rendus de Mécanique 331 (2003) 343-349.

[14] A.-L. Bulthé, Y. Desplanques, G. Degallaix, L. Sabatier, L. Delaye, Corrélation entre comportements tribologique et thermique sous deux types de sollicitations de freinage sévères pour le couple fonte à graphite lamellaire/Composite à matrice organique, Journées Internationales Francophones de Tribologie Tarbes France (2005).

[15] M. Siroux, Développement de techniques de mesure de l'émissivité de matériaux opaques à température ambiante. Approches radiométrique et calorimétrique en régime périodique, Thèse de l'Université Paris XII (1996).

[16] H.S. Carslaw, J.C. Jaeger, Conduction of Heat in Solids, second ed., Oxford University Press, 1959.

[17] M. Raynaud, Le problème inverse de conduction de la chaleur, Techniques de l'ingénieur, Genie énérgétique, BE 8265 (1998) 1-17. 